\title{
EN TORNO A LOS COMPLEMENTOS DOBLES O COMPLEJOS
}

\author{
$\mathbf{M}^{\mathrm{a}}$ Victorina Crego García \\ Universidade de Santiago de Compostela
}

\begin{abstract}
RESUMEN: En este artículo pretendemos analizar un tipo concreto de complemento de lugar que se combina con determinados verbos de movimiento. Se trata de un complemento locativo doble o complejo que consta de dos miembros, origen y destino, y que se analiza como un complemento o función.

Nos centraremos en la caracterización sintáctica, formal y semántica de los complementos dobles así como de los complementos de origen y destino que aparecen en la misma secuencia pero que constituyen dos funciones sintácticas distintas.

ABSTRACT: In this article we try to analyse a specific kind of place complement which is combined with motion verbs. We deal with a double place complement which consist of two members, source and goal, and that is analysed as a single complement or function.

We will focus on the syntactic, formal and semantic study of the double complements as well as on the analysis of the source and goal complements which appear in the same clause but that constitute two different syntactic functions.
\end{abstract}

PALABRAS CLAVE: Complemento locativo y verbos de movimiento.

KEYWORDS: Locative complement and verbs of movement.

0 . En el área de las secuencias organizadas en torno a los denominados verbos de movimiento $^{1}$ no es extraño detectar la copresencia de varios complementos locativos que corporeizan diferentes funciones semánticas (en líneas generales, eferencia u origen, aferencia o destino, locación y extensión). Junto a estos complementos que, sin ningún lugar a dudas, remiten a distintas funciones sintácticas de la naturaleza de:

(1) ... no iba a ser nada fácil continuar su ruta hacia el este, / pasar a la Macedonia griega a través del murallón / de los Balcanes $(C A R, 41,18)$

1. Nos referimos a verbos de movimiento que ofrecen la posibilidad de combinarse con complementos de lugar regidos, complementos adverbiales (CADV) en terminología de Rojo (1990). Vid. al respecto Crego García (2000: 87-117, 190-219). 
(2) El viejo acude veloz y abre / a tiempo de detener al angelito blanco acercándose ya / a la puerta desde la cuna $(S O N, 218,1)$

(3) ... y tiene parada en el piazzale de Biancamano / desde donde, por la vía Moscova y los jardines llegará / derecho a su casa $(S O N, 46,14)$

existen una serie de complementos locativos formados por dos miembros estrechamente relacionados, esto es, complementos dobles o complejos que configuran una unidad, un único complemento verbal (cfr. Guillet y Leclère, 1992: 32-33, 78-85). No obstante, en más de una oportunidad nos encontramos con que complementos que, a simple vista, pueden ser considerados una entidad compleja conforman, realmente, dos complementos de diferente naturaleza semántica o sintáctica, o de distinto perfil nocional pero idéntica categoría funcional, aunque el nivel externo formal sea semejante al de los complementos complejos indiscutibles.

A través del corpus sincrónico² que hemos manejado para realizar este trabajo, se ha constatado que, efectivamente, en algunas estructuras los verbos de movimiento aparecen acompañados de indicaciones de eferencia u origen y aferencia o destino pero que no siempre estas precisiones nocionales se materializan en el nivel sintáctico mediante una función sintáctica (el complemento doble o complejo), sino que en no pocas ocasiones la eferencia y la aferencia se corporeizan en complementos independientes de idéntica o distinta naturaleza sintáctica.

Asimismo hemos comprobado que en el seno de los complementos complejos se pueden distinguir dos subtipos en virtud del tipo de conexión sintáctica instaurada entre los dos polos que los constituyen: un subtipo que presenta relación de interdependencia entre ambos miembros y otro en el que la relación sintáctica imperante es la de determinación, siguiendo las distinciones y terminología de Hjelmslev (1943).

Precisamente, el objetivo que nos hemos marcado en este artículo es la distinción de los complementos complejos y, por supuesto, su caracterización sintácticoformal y semántica, punto de partida que supone la asunción de presupuestos teóricos que fundamenten nuestras decisiones. Estos presupuestos están adscritos, en líneas generales, al estructuralismo y funcionalismo europeos.

2. El estudio fue realizado tomando como punto de referencia ejemplos extraídos del Archivo de textos hispánicos de la Universidad de Santiago de Compostela (ARTHUS), tal y como han sido analizados en la Base de datos sintácticos del español actual (BDS). Esta base de datos sintácticos ha sido elaborada en el seno del proyecto de investigación Estructura de la cláusula y régimen verbal en español, cuyo investigador principal es Guillermo Rojo. El proyecto lo financió la Xunta de Galicia entre 1989 y 1991 (XUGA 82710088) y el Ministerio de Educación y Ciencia entre 1991 y 1994 (PB90 0376). En la última sección de estas páginas, Nómina de textos, incluimos los textos de los que hemos extraído las secuencias analizadas. 
1. Nos encontramos ante un complemento adverbial complejo (CADVc) en aquellos casos en que un verbo de movimiento rige un único complemento que integra las precisiones de eferencia u origen y de aferencia o destino ${ }^{3}$. La naturaleza compacta de los dos componentes se puede verificar a través de la imposibilidad de ambos, o al menos de uno de ellos, de sobrevivir independientemente. Esta doble alternativa estructural es la que da lugar a la distinción glosemática interdependencia/determinación que permitirá diferenciar dos tipos de CADVc. En opinión de Hjelmslev (1943: 42):

A las dependencias mutuas, en las que un término presupone al otro y viceversa, las llamaremos convencionalmente interdependencias. A las dependencias unilaterales, en las que un término presupone al otro, pero no viceversa, las llamaremos determinaciones. $\mathrm{Y}$ a las dependencias de mayor libertad, en las que dos términos son compatibles, pero ninguno presupone al otro, las llamaremos constelaciones.

Por tanto, considera que:

Podemos definir la interdependencia como función entre dos constantes; la determinación como función entre una constante y una variable, y la constelación como función entre dos variables (ibid.: 57).

1.1. En el seno de los CADVc más gramaticalizados o fijados, conviven dos constantes $(A \& B)$ que se necesitan mutuamente, de manera que la omisión de cualquiera de los dos miembros da lugar a una secuencia agramatical. Por supuesto, el tipo de conexión instaurada entre ambos constituyentes es la interdependencia.

3. Partimos de las distinciones funcionales que Rojo (1990) realiza en el ámbito de las funciones prepositivo-adverbiales nucleares del español. Recordemos que este investigador incluye en la función sintáctica complemento adverbial (CADV) los complementos de lugar exigidos por verbos de movimiento como ir, llegar, salir, acercar, poner o venir y por verbos de estado como estar, quedar y vivir.

En absoluto pretendemos ahondar en la dimensión valencial o no valencial de las precisiones locativas. En todo caso, recurriremos a distinciones funcionales como CADV, complemento intermedio y adjunto para vertebrar un mecanismo de clasificación de los distintos complementos locativos, en especial de los dobles o complejos. Para tales distinciones véanse los trabajos de Boons (1985), Cifuentes Honrubia (1988-1989), Crego García (2000: 184-219), Rojo (1990) y Somers (1984). En virtud de las ideas de estos investigadores partiremos de la premisa de que verbos de desplazamiento de la naturaleza de ir, venir o salir exigen complementos eferentes (encabezados por de) y complementos aferentes (encabezados por preposiciones como a, en, hacia, hasta y para), y de que verbos de modo de desplazamiento como andar, caminar, pasear o saltar no exigen complementos de lugar sino que, en todo caso, pueden combinarse con complementos intermedios o adjuntos (vid. infra apdo 2).

4. Vid. Rojo (1983: 50-51) y Rojo y Jiménez Juliá (1989: 44-46). 
Se trata de una construcción exocéntrica en el seno de la que se da la asociación indisoluble de dos constantes que conforman el complejo locativo origen-destino (cfr. Jiménez Juliá, 1997: 313-328 y González García, 1995). Hay que subrayar que ninguno de estos constituyentes forma parte de la combinatoria simple del verbo en torno al que se organizan eferencia y aferencia en bloque, comportamiento que, por supuesto, redunda en la naturaleza unitaria de los dos constituyentes que estructuran el CADVc.

La fijación formal y/o estructural de que hacen gala estos CADVc se traduce en una absoluta inmovilidad posicional de ambos polos (el eferente y el aferente), en la ausencia de determinantes y modificadores en el interior de estos y en la fijación numérica en el singular (componente no marcado de la categoría número) de los sustantivos que los conforman, en la imposibilidad de interpolación de otros elementos, en la fijación preposicional total en los dos miembros (eferencia: de / aferencia: en) y, finalmente, en la total rigidez léxica a través de la presencia de dos piezas léxicas idénticas:

(4) Un poquito / de silicona por aquí, unos retoques por allá y ¡hala!, / lista para ir de cama en cama con quien se presente $(P A S, 066,3) \rightarrow \ldots$ * lista para ir de cama con quien se presente en cama / ... * lista para ir de una(s) cama(s) en otra(s) cama(s) con quien se presente / ... * lista para ir de/desde cama a/hacia/hasta/para cama con quien se presente / ...* lista para ir de cama en casa con quien se presente.

(5) En / este punto intervine yo rogando al monje que se / dejara de niñerías y que, si quería sernos de utilidad, fuera de celda en celda despertando a sus / correligionarios... (LAB, 242, 24) $\rightarrow \ldots$ * fuera de celda despertando a sus correligionarios en celda / ...* fuera de una(s) celda(s) en otra(s) celda(s) despertando a sus correligionarios / ... fuera de/desde celda a/hacia/hasta/para celda despertando a sus correligionarios / ... * fuera de celda en casa despertando a sus correligionarios.

(6) En verano solía / tocar el bajo en una orquesta que iba por los pueblos de verbena en verbena y $\ldots(T E R, 098,5) \rightarrow \ldots *$ iba de verbena por los pueblos en verbena $\mathrm{y} . . . /$. $^{*}$ iba por los pueblos de una(s) verbena(s) en otra(s) verbena(s) y ... /..* iba por los pueblos de/desde verbena a/hacia/hasta/para verbena $\mathrm{y} . . . / \ldots *$ iba por los pueblos de verbena en fiesta $\mathrm{y} . .$.

A tenor de su comportamiento formal, cabe concluir que se trata de estructuras lexicalizadas en las que se da una especie de imbricación espacio-modal ${ }^{5}$. Esta

5. Por consiguiente, configuran construcciones que han de ubicarse en el marco del discurso repetido y no en el de la técnica libre del discurso (vid. Coseriu, 1981: 297-301). Cfr. infra nota 15. 
naturaleza lexicalizada se ve reafirmada por el hecho de que la entidad prepositiva $e n^{6}$, a priori de contenido locativo-estativo, parece haber perdido, o por lo menos atenuado, ese valor estativo, además de que hoy en día -sí en el español medievalno es una entidad prepositiva regida por el verbo ir (como tampoco lo es de), por lo menos en el nivel de uso en el que nos movemos. Esta tipología estructural no pasa el tamiz de estructuras enfatizadoras como las ecuandicionales ${ }^{7}$ que reflejan, aunque sea de forma aproximada, la naturaleza semántica (y la sintáctica) de los complementos, naturaleza que se manifiesta dinámica y no locativa, como podemos comprobar en la parte hipotética de la construcción ecuandicional que tolera entidades prepositivas como de...a y no de...en:

(7) ... lista para ir de cama en cama con quien se presente $\rightarrow$ Si va de un lugar a otro lugar con quien se presente es de cama en cama / * Si va de un lugar en otro lugar con quien se presente es de cama en cama.

Asimismo, este tipo de estructuras constata que se trata de una única función sintáctica y no de dos:

(8) ... lista para ir de cama en cama con quien se presente $\rightarrow \ldots *$ si va de un lugar es de cama / ...* si va a un lugar es en cama

Como ya hemos mencionado anteriormente, la fijación formal, sintáctica y nocional de estos CADVc se encuentra asociada a una rigidez casi absoluta en los tres planos mencionados, con la única salvedad de que estos complementos permiten en bloque el mecanismo informativo de la tematización y toleran una gran libertad distribucional en el eje remático, eso sí, siempre y cuando el traslado posicional no vulnere el bloque que forman eferencia y aferencia. Esta invulnerabilidad

6. En todo caso, el valor locativo-estativo de esta preposición se conserva en el nivel interno, esto es, en el marco de la estructura interdependiente, y no con respecto a la entidad verbal de la que depende indirectamente.

7. Gutiérrez Ordóñez (1994: 368-369, 379, 381-383; 1996: 438) defiende la operatividad de las estructuras ecuandicionales para discriminar si estamos ante funciones sintácticas nucleares o marginales. Como podemos comprobar en los ejemplos que siguen, cuando operamos con entidades nucleares estas tienen que aparecer geminadas en la parte hipotética de la construcción ecuandicional a través de pronombres indefinidos (precedidos o no de la correspondiente preposición) (vid. infra a-b), en tanto que tal geminación no es necesaria si nos encontramos ante entidades marginales (vid. infra c):

a. Le di dinero a Pedro $\rightarrow$ Si di dinero a alguien fue a Pedro / ? Si di dinero [...] fue a Pedro.

b. Siempre dependí de mis padres $\rightarrow$ Si siempre dependí de alguien fue de mis padres / * Si siempre dependí [...] fue de mis padres.

c. Me encontré con Pedro ayer $\rightarrow$ Si me encontré con Pedro fue ayer. 
supone que, precisamente, ambos componentes aparecen distribuidos en un único orden: eferencia-aferencia, tal y como es el comportamiento prototípico de las dos constantes que entran en la relación de interdependencia distinguida por el maestro holandés. En consecuencia, la linealidad o secuencialidad de estas constantes impide traslados distribucionales del tipo de:

(9) ... lista para ir de cama en cama con quien se presente $\rightarrow \ldots *$ lista para de cama ir en cama con quien se presente $/ . . . *$ lista para ir en cama de cama con quien se presente / ... * lista para ir de cama con quien se presente en cama,

aunque sí es factible, como ya habíamos indicado, la tematización o rematización en bloque:

(10) ... lista para ir de cama en cama con quien se presente $\rightarrow$... lista para de cama en cama ir con quien se presente / ... lista para ir con quien se presente de cama en cama.

Asimismo, hay que señalar que en el corpus con el que hemos trabajado ir es la única entidad verbal que se combina con este tipo de complemento, especialización que puede responder a su naturaleza hiperonímica en el ámbito de los verbos de desplazamiento ${ }^{8}$. Además, debemos tener en cuenta que es el verbo de desplazamiento que ofrece un nivel de uso más elevado, por lo menos en el corpus que nos sirve de punto de referencia.

1.2. Por su parte, los CADVc por determinación constan de un miembro constante (la aferencia o destino) y un miembro variable (la eferencia u origen) (A\&(B)). Esta constitución, pues, supone que la constante puede sobrevivir, estructuralmente hablando, sin la variable, pero no a la inversa:

(11) ... con lo que pasé sin transición / y como tantas veces me ha sucedido en la vida, / de agudo espectador a perplejo protagonista ( $L A B$, $21,19)^{9} \rightarrow \ldots$ con lo que pasé $[\ldots]$ a [ser] perplejo protagonista / ...* con lo que pasé $[\ldots]$ de $\left[\right.$ ser] agudo espectador. ${ }^{10}$

8. Para la oposición léxica y sintáctico-semántica verbos de desplazamiento / verbos de modo de desplazamiento, véanse los trabajos de Cifuentes Honrubia (1988-1989) y de Crego García (2000: 102ss.). 
(12) ...pero Dilia no, Dilia lentamente / yendo de la mesa hacia la cama con una / mano buscando ya el cierre de los jeans... (GLE, 143, 15) $\rightarrow$... Dilia lentamente yendo hacia la cama con una mano... / .. * Dilia lentamente yendo de la mesa con una mano...

Estos CADVc se enclavan en la construcción endocéntrica o hipotáctica que, retomando tesis de investigadores que lo anteceden, caracteriza Jiménez Juliá (1997: 313-328; 2000: 109-114, 120-125) en el marco de una gramática constitutivo-funcional ${ }^{11}$. Según este autor, las configuraciones endocéntricas constan de un núcleo o constante y de una expansión o variable que amplía, restringiendo, la vertiente referencial o comunicativa del núcleo, sin modificar en absoluto su valor semántico general ni su capacidad integrativa. Como se puede deducir, el tipo de conexión instaurada entre núcleo y expansión es el de subordinación, de manera que el núcleo es la entidad subordinante que siempre ha de mostrar autonomía sintáctico-semántica y la expansión la subordinada que carece de tal autonomía.

En las construcciones endocéntricas que nos ocupan el núcleo remite a una estructura prepositiva exocéntrica (el polo aferente) que, a su vez, sufre la expansión o ampliación a través de otra estructura prepositiva exocéntrica (la eferencia). El orden secuencial que las preside es el considerado por Jiménez Juliá orden marcado, en tanto en cuanto la expansión ocupa la posición prenuclear, frente a la posición posnuclear propia de las expansiones que responden a un orden distribucional no marcado. Este orden marcado es semejante al de los denominados adjetivos epítetos, explicativos o no restrictivos que implican una

\footnotetext{
9. El verbo pasar admite en su combinatoria simple (por tanto, en aquellas estructuras carentes de complemento doble o complejo) la presencia de un complemento eferente o de origen, lo que nos podría haber inclinado a incluir estructuras como esta y las siguientes en el apartado 3 (vid. infra). No obstante, hemos constatado que este verbo rige origen cuando significa 'sobrepasar, franquear un límite espacial', como en las secuencias:

O sea, sé que siempre lo tengo más o menos hecho y / yo, de, de, freírte un bistec o unas patatas de ahí no paso (MAD, 382, 29).

La señorita no puede pasar del vestíbulo, porque va con / pantalones $(L A B, 227,6)$.

En aquellas construcciones en las que pasar va acompañado de eferencia y aferencia adquiere un significado similar al del verbo ir: 'desplazarse de un lugar a/hacia otro', tal y como sucede en las estructuras que estamos analizando. Precisamente, en esta tipología construccional no se puede prescindir del componente subordinante, la aferencia.

10. En esta prueba ha sido necesario insertar el verbo ser debido a que estamos ante una configuración abstracta, derivada de la física prototípica. Vid. infra nota 18.

11. Vid. González García (1995: 553-556).
} 
dimensión nocional sobrentendida, tal y como, posiblemente, sucede en el ámbito de estos CADVc con respecto a la información vinculada al polo eferente. Asimismo, cabe destacar que la expansión se une al núcleo a través de un recurso directo como la yuxtaposición: la entidad prepositiva de depende del verbo y no del núcleo.

¿Por qué es la aferencia, y no la eferencia, la entidad subordinante o constante? Es posible que esta prioridad estructural esté entroncada con la prioridad conceptual o cognitiva de la aferencia sobre la eferencia en el proceso de aprendizaje del esquema locativo, tal y como admite Dervillez-Bastuji (1982: 310) ${ }^{12}$ :

Du point de vue spatial, le point notable pour le Déplacement est que "l'afférence", c'est-à-dire la direction vers un lieu avec ou sans atteint de ce lieu, est acquise plus précocement que "l'efférence". [...] Lorsqu'on montre à un enfant un déplacement, l'enfant considère d'abord le terme, puis considère à la fois le terme et l'origine, puis enfin considère le terme, l'origine et le déplacement lui-même. Observations qui [...] confirment la priorité de l'afférence sur l'efférence, et la priorité de l'etat résultatif sur le déplacement manifestée chez le trés jeune enfant.

Esta preeminencia cognitiva se materializa en el nivel lingüístico en la cadena eferencia (variable)-aferencia (constante), frente a la nivelación lingüística existente en el CADVc por interdependencia.

Este subtipo de CADVc por determinación comparte con el anterior la propiedad de la especialización formal en el polo eferente, pero no en el aferente, en el seno del que se produce una relativa variedad preposicional. De hecho, podemos comprobar en las secuencias siguientes que la parte del complemento que indica destino puede ir encabezada por tres preposiciones que codifican valores nocionales relativamente distintos: la preposición más frecuente es $a$ (indica aferencia puntual); en segundo lugar, para es la entidad prepositiva más utilizada para indicar aferencia orientativa y final (realizada); y, en último término, de uso mucho menos prolijo es la preposición hacia que remite a la aferencia orientativa, no necesariamente realizada (cfr. Morera Pérez, 1988 y Trujillo, 1971):

(13) ... con lo que pasé sin transición / y como tantas veces me ha sucedido en la vida, / de agudo espectador a perplejo protagonista (LAB, 21, 19).

12. Vid. Cifuentes Honrubia (1988-1989) y Crego García (2000: 190-201). 
(14) Pasaba de la alegría a un / sordo fastidio por la presencia de Massey en el palco (HIS, 32, 13).

(15) Va enloquecida de un lado para otro (HOT, 49, 34).

(16) ...pero Dilia no, Dilia lentamente / yendo de la mesa hacia la cama con una / mano buscando ya el cierre de los jeans... (GLE, 143, 15).

Tal y como sucedía en el grupo de los CADVc por interdependencia, los polos eferente y aferente de los CADVc por determinación mantienen un orden único: el componente subordinado o variable (la eferencia) siempre va antepuesto al componente subordinante o constante (la aferencia), distribución que, además, en la mayor parte de las ocasiones aparece asociada a un bloque secuencialmente compacto:

(17) ... cogía morosamente y pasaba / de una mesa a otra, apenas con el pantalón de la pijama (DIE, 63, 16).

(18) ¡Que no me pasaran su costal de palabras / muertas, sus actos fallidos, sus vidas inconclusas, sus jardines / sin gente, sus ansias, sus agujas sin hilo, sus bordados, que llevaban de una pieza a otra, sus letanías inhábiles... (DIE, 168, 5). ${ }^{13}$

13. Asimismo, llevar, en uso no pronominal, incluye en su combinatoria simple el complemento eferente en aquellos contextos en que activa la acepción de naturaleza estática 'coger algo de un lugar', como podemos constatar en las secuencias:

Jano había escrito / que llevaron a Francesca de su lado $(C A R, 24,10)$

Otras versiones / apuntan a que el homicida llevaba / la herramienta, utilizada / en trabajos de cantería, de su / propia casa $(2 \mathrm{VO}, 26,1,2,18)$,

comportamiento semejante al de la variante pronominal con eferencia (con el valor añadido, en este caso, de inceptividad o incoatividad):

Rafa, llevándose de la barra una / copa, va a reunírseles, también pausadamente $(O C H, 48,1)$.

En las secuencias en las que llevar(se) se combina con un complemento aferente o de destino obligatorio (con la posibilidad de aparición de otro de origen) adquiere el significado claramente dinámico de 'desplazar algo de un sitio a otro'. Esta acepción es la que activa en las estructuras de CADVc que son objeto de estudio. 
(19) Y comienza a ir / de un lado a otro (CAI, 95, 6).

(20) Si no, mientras iba de un quehacer a otro, guardaba / silencio (DIE, 68, 5).

Como podemos comprobar en esta última serie de ejemplos (supra (17)-(20)), además de en la secuencia (15), en aquellos complementos en los que es el mismo sustantivo el núcleo de las dimensiones eferencia y aferencia se activa el mecanismo de la deíxis y el de la omisión a través de la no repetición del sustantivo en el segundo miembro. Esta ausencia de redundancia léxica es sustituida por el pronombre indefinido otro que, como entidad pronominal que es, y mediante la referencia anafórica, remite a la pieza léxica que lo precede ${ }^{14}$. Esta, nuevamente, constituye otra propiedad diferencial con respecto a los CADVc por interdependencia, en el marco de los que se repetía idéntica pieza léxica como única alternativa estructural.

No obstante, en esta clase de complementos por determinación nos encontramos con una variante estructural inexistente en la anterior tipología: la posibilidad de tematización del componente eferente, mecanismo que, en ningún caso, se puede extender al miembro aferente:

(21) De allí pasa a un recinto con varios aparatos y... (SON, 70, 13).

(22) De ahí se pasó / a discutir la agresividad humana o animal y los dos / profesores se enzarzaron acerca de la clave del comportamiento (SON, 314, 2).

(23) De un jardín cercano subía hasta el balcón un intenso / olor a rosas $(\mathrm{JOV}, 123,13)$.

Esta posibilidad parece estar asociada al hecho de perfil conceptual y semántico que estipula que el origen de un desplazamiento es necesariamente anterior el destino, cadena locativa que impide que la aferencia preceda a la eferencia, siempre y cuando la eferencia no tenga como significante gramatical un adjunto (vid. infra apdo 4).

Aun siendo la tematización parcial el rasgo más distintivo de esta clase de CADVc con respecto al CADVc por interdependencia, también cabe señalar que los miembros del CADVc por determinación permiten la presencia de información interpuesta a modo de aposición:

14. Este tipo de CADVc no ofrece, en el corpus que nos sirve de referencia, la posibilidad de aparecer tematizado, comportamiento que se puede deber a que vertebra una estructura más gramaticalizada (eferencia nominal + aferencia pronominal) que la de los restantes complementos integrados en este subtipo. 
(24) ... y pasé de allí, desde ese colegio, a otro / colegio también cercano, por aquella zona... (SEV, 16, 10).

Como se puede desprender del análisis de las anteriores secuencias, el polo eferente nunca puede aparecer pospuesto al aferente.

Por otra parte, hay que destacar la importancia de la potencialidad valencial del verbo que se combina con cada CADVc, habida cuenta de que sólo los verbos que toleran en su combinatoria simple un CADV de destino, no de origen, admiten este CADVc. En este subtipo concreto aumenta sensiblemente el número de verbos que lo articulan; frente a la exclusividad de ir en el anterior grupo, en este nos encontramos con tres verbos que se combinan con CADVc: ir, pasar y llevar. En consecuencia, a una menor rigidez verbal le corresponde una menor rigidez en los miembros eferente/aferente de los CADVc.

2. La categoría complemento doble o complejo también aparece en estructuras en las que este no tiene naturaleza nuclear o valencial sino intermedia, siguiendo las distinciones funcionales de Somers (1984). Se trata de un tipo de complemento previsible semántica y sintácticamente por parte de clases generales de verbos, en este caso, de verbos de modo de desplazamiento como andar, caminar y pasear:

(25) A alguien que / no resistió la tentación de preguntárselo, un poco antes / de la boda, le contestó: "Andaba de pueblo en pueblo buscando con quien casarme" (CRO, 32, 6).

(26) De hecho, podía andar de un / lado para otro sin que ninguno se preocupara de / recordarle que debía guardar reposo $(T E R, 080,5) .{ }^{15}$

(27) Bruscamente se levantó de la silla y se puso a caminar / (y a renguear), de un lado a otro, por el cuarto (HIS, 164, 23). ${ }^{16}$

15. La presencia obligatoria del determinante en esta secuencia y en la siguiente debe ubicarse en el marco del discurso repetido y no atribuirse a la técnica libre del discurso, ya que los elementos de estos complementos "no son lingüísticamente "estructurables" porque, en la medida en que son fijos, no son sustituibles ("conmutables") y, por consiguiente, no participan en oposiciones funcionales actuales" (Coseriu, 1981: 297-302).

16. En las secuencias (25)-(27), en el interior de las que nos encontramos con un complemento doble absolutamente gramaticalizado (de pueblo en pueblo) y dos menos gramaticalizados que activan el mecanismo deíctico (de un lado a/para otro), la dimensión modal de 'inquietud' parece fundirse con la propiamente locativa, comportamiento que no detectamos en la estructura (28) que no comparte la propiedad modal. 


\section{Ma VICTORINA CREGO GARCÍA}

(28) Fue su última actuación, injustamente / abrumada por una prensa mediocre que habló / perentoriamente de tomadura de pelo; desde entonces, / el músico había paseado discretamente la indemne / y llamativa peluca de la academia de idiomas / a su minúsculo apartamento... (PAI, 65, 25).

Si les aplicamos a estos complementos las propiedades detectadas en los anteriores tipos, constataremos que se trata de complementos interdependientes que no toleran la omisión de ninguno de sus dos miembros constantes, y que muestran idéntica rigidez distribucional o posicional que la de los complementos interdependientes ya analizados, aunque una superior variedad formal (o prepositiva) que la que habíamos detectado en estos (eferencia: de / aferencia: $a$, en ${ }^{17}$ y para):

(29) ... y se puso a caminar (y a renguear), de un lado a otro, por el cuarto $\rightarrow \ldots *$ y se puso a caminar (y a renguear), de un lado, por el cuarto $/ \ldots *$ y se puso a caminar (y a renguear), a otro, por el cuarto / y...* de un lado se puso a caminar (y a renguear) a otro, por el cuarto / ...* y a otro se puso a caminar (y a renguear), de un lado, por el cuarto.

Un verbo de modo de desplazamiento como saltar incluye aparentemente la misma posibilidad combinatoria. Sin embargo, si trascendemos el nivel de la apariencia formal, podremos verificar que los polos eferente y aferente que se combinan con esta entidad verbal constituyen dos funciones sintácticas diferentes (también de naturaleza intermedia, no valencial) que pueden llegar a coocurrir en la misma secuencia, pero que asimismo forman parte de su combinatoria simple, por lo menos de forma clara los polos eferente y aferente de valor físico (infra $(31))^{18}$ :

(30) Empiezas a saltar de un / recuerdo a otro, a dar vueltas en la cama, y se acabó $(C I N, 66,23) \rightarrow$ ? Empiezas a saltar de un recuerdo, a dar vueltas en la cama... / empiezas a saltar a otro [recuerdo], a dar vueltas en la cama...

(31) ¡Sacadme, que me ahogo! / (Loristo, saltando del brocal al suelo, enlaza por la / cintura a Gatina y así caminan hacia el mutis.) (INF, 28, 3) $\rightarrow \ldots$ Loristo, saltando del brocal, enlaza por la cintura... / ... Loristo, saltando al suelo, enlaza por la cintura...

17. Como podemos observar, esta preposición aparece exclusivamente en los complementos dobles más gramaticalizados que hemos analizado anteriormente.

18. Consideramos, como García-Miguel (1995: 105), que las secuencias no físicas (desviadas o metafóricas) constituyen variantes nocionales derivadas de la invariante significativa propia de la función preposicional CADV. Por tanto, el análisis lingüístico será semejante al de las relaciones locales prototípicas, erigiéndose el mantenimiento de la misma forma verbal en el factor fundamental que marca la contigüidad entre ambos tipos de estructura. 
3. Efectivamente, en muchas ocasiones, coocurren en la misma secuencia eferencia y aferencia encarnadas ya no en un significante sintáctico complejo (complemento doble) sino en dos significantes o funciones sintácticas (cfr. Rojo, 1979). Como podemos comprobar en las estructuras que siguen, una amplia batería verbal formada por verbos como bajar, caer(se), descender, enviar, huir, irse, llegar, salir y subir, se combina con dos CADV, por tanto, con dos funciones sintácticas nucleares ${ }^{19}$ :

(32) ... para darme un resuello había bajado, por unos / segundos, de la punta a la planta de los pies... (HIS, 134, 26). ${ }^{20}$

(33) ... baja las escaleras como cuando descendía de la / montaña a Roccasera en víspera de fiestas (SON, 172, 4).

(34) ... causado sorpresa el hecho de que / desde Bruselas se esté defendiendo / la integridad de los caladeros, / y por otra parte se envía a toda la / flota que sobra de España a Argentina (1VO, 40, 3, 2, 27).

(35) También hubiera querido huir de aquella música, / como huía de tu voz hacia el fondo del jardín en los / días que pasamos en Como (CAR, 173, 24).

(36) ... llevando en su interior / el mismo vacío, igual inquietud que cuando había / llegado de Italia al balneario (CAR, 178, 31).

(37) ... la entrada en / las pocas curvas de la línea nos dice infaliblemente / si salimos de Congreso hacia Sáenz Peña o remontamos / hacia Loria (GLE, 53, 32).

19. Aun cuando desde la óptica cognitiva o conceptual y desde el parámetro de la cohesión (vid. Crego García, op. cit.: 195ss.) la aferencia es prioritaria con respecto a la eferencia, en el nivel sintáctico pueden convivir dos CADV nucleares (uno aferente y otro eferente), si bien la tendencia general es que los verbos de desplazamiento rijan un único CADV (o aferente o eferente). De hecho, no hemos encontrado ningún mecanismo formal inmanente que sustente la prioridad sintácticosemántica de la aferencia en los casos en que convive con la eferencia (con de): ni el test del proverbo hacer ni la construcción ecuandicional:

... descendía de la montaña a Roccasera $\rightarrow$... * descendía de la montaña y lo hacía a Roccasera / ... * descendía a Roccasera y lo hacía de la montaña / ... * si descendía de algún lugar era de la montaña a Roccasera / ... * si descendía a algún lugar era a Roccasera de la montaña.

20. Frente a la deíxis anafórica detectada en los CADVc, en esta tipología construccional encontramos ejemplos como este en los que, mediante la deíxis catafórica, se omite el modificador del sustantivo del polo eferente. 


\section{Ma VICTORINA CREGO GARCÍA}

Para verificar que estamos ante dos funciones sintácticas diferentes, recurrimos a la combinatoria simple de cada verbo y a las estructuras ecuandicionales, que aplicamos exclusivamente, a modo de ilustración, a las secuencias de bajar y descender:

(38) ... para darme un resuello había bajado, por unos / segundos, de la punta a la planta de los pies... $\rightarrow \ldots$ había bajado de la punta [de los pies]... / ... había bajado a la planta de los pies... / si había bajado de un lugar a otro fue de la punta a la planta de los pies / si había bajado de algún lugar era de la punta de los pies / si había bajado a algún lugar era a la planta de los pies.

(39) ... baja las escaleras como cuando descendía de la / montaña a Roccasera en víspera de fiestas $\rightarrow$... baja las escaleras como cuando descendía de la montaña... / baja las escaleras como cuando descendía a Roccasera... / si descendía de un lugar a otro era de la montaña a Roccasera... / si descendía de algún lugar era de la montaña / si descendía a algún lugar era a Roccasera.

Ambos verbos, así como el resto de los incluidos en esta tipología funcional, incorporan en su combinatoria simple dos complementos locativos (eferente y aferente), posibilidad inexistente en el seno de las construcciones de CADVc (vid. supra apdos 1 y 2).

Asimismo, cabe señalar que gran parte de las estructuras integradas en este apartado presentan los dos CADVs respetando el orden lineal existente en los CADVc: eferencia-aferencia. No obstante, es factible que el CADV eferente aparezca tematizado (no así el aferente), tal y como podemos constatar en las construcciones que siguen:

(40) Y de las nubes de aquel / paraíso ficticio se caía sin transición -cuando se caía- en los / raíles del noviazgo con un muchacho concreto... (USO, 160, 27).

(41) De allí me fui a otro colegio, a las / Teresianas, en donde estudié el bachiller hasta / cuarto y luego hasta sexto y después, de allí, me / fui a la Normal que hice los tres años de la carrera / de Magisterio (SEV, 91, 12/15).

(42) De aquí a / Cádiz se llega en menos de una hora... (SEV, 7, 31).

(43) Porque de la pasión / por una idea se podía llegar incluso al crimen (USO, 070, 31). 
Como ya habíamos resaltado con anterioridad, esta es una posibilidad construccional asociada a la anterioridad conceptual y semántica del origen de un desplazamiento con respecto al destino, cadena locativa que impide que la aferencia preceda a la eferencia, siempre y cuando la eferencia no tenga como significante gramatical un adjunto (vid. infra apdo 4).

4. Por último, queremos dejar constancia de que los complementos eferentes con desde son complementos no nucleares adjuntos, dado que ni responden a las exigencias sintáctico-semánticas de los verbos de movimiento (por tanto, no son funciones nucleares), ni a la previsibilidad sintáctico-semántica de los complementos intermedios propia de clases generales de verbos. Se trata de funciones adjuntas en virtud de que constituyen información adicional susceptible de combinarse con cualquier clase de verbo ${ }^{21}$ (cfr. Somers, 1984). Esta ausencia de restricciones sintácticas y semánticas fundamenta la amplia gama de verbos de movimiento con los que se combinan estos complementos y la copresencia, en las estructuras en las que aparecen, de cualquier tipo de complemento locativo de los que hemos distinguido: CADV aferente o eferente y complemento intermedio de extensión, origen y destino.

Efectivamente, estos complementos eferentes adjuntos coocurren, en muchas ocasiones, con CADV aferentes (encabezados por preposiciones como $a$, hacia, hasta, sobre). En aquellas estructuras en las que, en el nivel secuencial, preceden a la aferencia forman un bloque semántico con este polo, pero no sintáctico, habida cuenta de que ambos componentes nocionales se materializan, como ya hemos dicho, en dos funciones sintácticas distintas (CADV y adjunto) (cfr. infra (44) y (45)):

(44) Se le quedó grabada la estampa cuando / bajó un domingo desde el monte a Roccasera, llevando / al cuello un cabritillo para el señor marqués... (SON, 171, 11) $\rightarrow$... si bajó un domingo desde un lugar a otro lugar fue desde el monte a Roccasera / ... si bajó a un determinado lugar fue, desde el monte, a Roccasera / fue a Roccasera, desde el monte.

21. Básicamente, lejos de constituir un continuum sintáctico-semantico con respecto al verbo, enmarcan o encuadran espacialmente la estructura en la que se integran, desempeñando, en muchas ocasiones, la que determinados autores consideran función incidental. Esta posición incidental está asociada a la distribución parentética y a una especie de predicación secundaria paralela a la propia del verbo que organiza la estructura oracional o clausal dominante (cfr. Gutiérrez Ordóñez, 1997 y Martínez, 1994). 
(45) ... han / elevado el volumen de negocio de la sociedad / desde los 1.573 millones de pesetas / de 1988 hasta los 1.837 millones del último / ejercicio $(2 V O, 57,1,5,22) \rightarrow \ldots$ si han elevado el volumen de negocio de la sociedad desde una cantidad de pesetas hasta otra cantidad fue desde los 1.573 millones hasta los $1.837 \ldots$ / ... si han elevado el volumen de negocio de la sociedad hasta una cantidad $\mathbf{x}$ de pesetas fue, desde los 1.573 millones de pesetas, hasta los $1.837 .$. / fue hasta los 1.837, desde los 1.573 millones de pesetas ${ }^{22}$.

(46) Un resplandor / escarlata descendía desde un cielo sin nubes a la tierra... (JOV, 92, 40).

(47) Entre tanto, los hijos van y vienen / cautelosos desde la alcoba a la cocina, vistiéndose / mientras muerden las tostadas salidas del aparato (SON, 31, 23).

(48) Arresto mayor, / que va desde un mes y un día hasta seis meses $(S E V, 147,11)$.

(49) ... las luchas, en una vasta región / que va desde Afganistán a los Himalayas, entre las 7 ambiciones imperiales rusas y las de Occidente (TIE, 106, 26).

(50) ... y al instante se hubiese convertido, / por un hechizo lanzado desde el hoy hacia sus ojos, en estatua de sal (RAT, 211, 23).

(51) ¿Recuerdas / cómo los Severini llevaron un carrito de mano desde / Montparnasse hasta más allá de la barrera de Montrouge...? (DIE, 13, 6).

22. Dado que los complementos locativos regidos de estas secuencias son los CADV aferentes, las construcciones ecuandicionales muestran que sólo los adjuntos eferentes pueden aparecer en el período no hipotético sin la presencia de una entidad prepositiva correferencial en el período hipotético, además de poder ir antepuestos o pospuestos al componente aferente a modo de inciso explicativo (vid. supra (44) y (45)). En contrapartida, los CADV aferentes no pueden verse reflejados en el miembro no hipotético sin ser mencionados previamente en el polo hipotético ni ser presentados mediante una explicación adicional a la eferencia:

... ?? si bajó desde un determinado lugar fue desde el monte, a Roccasera / ?? fue, a Roccasera, desde el monte.

... ?? si han elevado el volumen de negocio de la sociedad desde una cantidad $\mathrm{x}$ de pesetas fue desde los $\mathbf{1 . 5 7 3}$ millones de pesetas, hasta los 1.837 millones.../ ?? fue, hasta los 1.837 millones de pesetas, desde los 1.573 millones de pesetas. 
(52) ... las manchas moradas o rojas que subían desde / los muslos y el sexo hasta los senos donde ahora / volvía a apoyarse la brasa con una escogida delicadeza... (GLE, 076, 23).

Aunque la distribución más frecuente de estos complementos con desde es la presentada en las secuencias anteriores, a tenor de su naturaleza adjunta ofrecen una amplia gama de posibilidades posicionales, entre las que se encuentra la tematización junto al componente aferente:

(53) Desde el estómago / hasta la garganta le subió un vacío doloroso (JOV, 52, 7),

la tematización en solitario:

(54) Logrado / esto, vemos cómo el Pájaro Carpintero, desde lo más / alto de un árbol, se lanza vertiginosamente sobre los / cerrados ojos del León y se los pica... $(1 I N, 21,3)$

(55) Lugo tuvo que retirar ayer la nieve / existente en la carretera de Sete / Carballos a Quindós y en el ramal / que desde la misma lleva a Nudelos / y Los Olmos... (3VO, 27, 2, 1, 6),

la posición explicativa, a modo de inciso:

(56) ... y yo tuve la extraña / sensación de que las dos habíamos llegado al mismo / tiempo, desde naufragios diferentes, a la isla salvadora (JOV, 108, 24),

y, como no, la posición final absoluta (con respecto al verbo del que depende):

(57) El viejo acude veloz y abre / a tiempo de detener al angelito blanco acercándose ya / a la puerta desde la cuna $(S O N, 218,1)$.

(58) Yo no sé si estuviste en Monteoscuro / o si, llegando a ella desde la llanura, te espantó / al atardecer... (CAR, 19, 19).

(59) Llegó hasta nuestra playa de Bretaña / desde su caserío de Ataun $(\mathrm{JOV}, 134,5)$.

(60) ... una vez que Yavé no lo miraba atribuyó a inspiración de su inmortal / señor palabras que no eran sino un suspiro que le subía a los labios / desde sus propias entrañas de mortal... (RAT, 227, 10). 
Por supuesto, estos complementos adjuntos, que muestran una predisposición clara a la posición temática, se combinan también, además de con CADV aferentes, con complementos intermedios de extensión:

(61) Desde Santurce a Bilbao / vengo por toda la ría... (HOT, 83, 4)

(62) Desde los montes cercanos, los olores subían / por las calles estrechas hasta el corazón de la ciudad (JOV, 95, 32)

(63) Desde lo alto de la torre, bajaron en un bote, / a gran velocidad, por un tobogán, hasta el lago (HIS, 80, 20)

(64) ... y tiene parada en el piazzale Biancamano / desde donde, por la vía Moscova y los jardines llegará / derecho a su casa (SON, 46, 14),

con complementos intermedios aferentes:

(65) ... pero no / alcanzaba a ver a su hijo que corría desde otro ángulo / hacia la puerta $(C R O, 115,11)$

(66) Desde otra ventana invisible salta al aire una / saeta de luz (SON, 346, 1),

y con complementos intermedios aferentes y de extensión:

(67) Paseábase el rey moro / por la ciudad de Granada / desde la puerta de Elvira / hasta la de Bibarrambla (HOT, 12, 1).

5. El análisis de los complementos locativos que habitualmente acompañan a verbos de movimiento nos ha permitido identificar y caracterizar aquellas entidades funcionales dobles o complejas que integran dos miembros: la eferencia u origen y la aferencia o destino. Estos complementos dobles han de ser analizados como un todo, un único significante sintáctico que no permite el análisis aislado de, al menos, uno de sus miembros.

En virtud, precisamente, de la posibilidad de segregar uno o ninguno de los dos polos de los complementos dobles hemos diferenciado, respectivamente, complementos dobles por determinación de complementos dobles por interdependencia, siguiendo las distinciones de Hjelmslev.

En consecuencia, hemos distinguido un CADVc (por tanto, exigido por la entidad verbal con la que se combina) por interdependencia o exocéntrico que 
representa la clase funcional más gramaticalizada, habida cuenta de que hace gala de una fijación formal, distribucional y nocional casi absoluta que implica fijación prepositiva completa e imposibilidad de separar los dos miembros que lo estructuran. Esta naturaleza rígida, prácticamente lexicalizada, se corresponde con la especialización verbal: teniendo en cuenta el corpus del que hemos partido, este CADVc sólo se combina con el representante hiperonímico de los verbos de desplazamiento, el verbo ir.

Por su parte, el CADVc por determinación o endocéntrico da entrada, si bien es cierto que de forma sensible, a dos verbos más: además de ir(se), llevar y pasar. Como el anterior tipo, este CADVc ofrece una absoluta fijación formal en el polo eferente a través de la presencia exclusiva de la preposición de, pero, a diferencia del CADVc por interdependencia, manifiesta una superior riqueza preposicional en el miembro aferente, la posibilidad de interposición de una aposición entre los dos constituyentes que lo estructuran y la tematización de la eferencia. En ambos casos, el polo eferente debe anteceder siempre al aferente.

En el ámbito no valencial de los complementos intermedios, hemos detectado la presencia de complementos dobles o complejos (interdependientes) en compañía de verbos de modo de desplazamiento de la naturaleza de andar, caminar y pasear, en el seno de cuyas estructuras nos hemos encontrado con un comportamiento formal, distribucional y nocional relativamente semejante al existente en las construcciones de CADVc por interdependencia. Las diferencias que los oponen a estas últimas, además de las pertenecientes al eje valencial, están ubicadas en la superior variedad formal (prepositiva) de la que hace gala su polo aferente.

Y, en último término, también nos hemos centrado en aquellas secuencias de verbos de desplazamiento (v.gr., bajar, descender, enviar, huir, llegar y salir) que, aunque desde el punto de vista más externo se asemejan a las estructuras de CADVc, son configuraciones que constan de dos funciones sintácticas distintas, dos CADV: uno eferente y otro aferente. Esta alternativa construccional está asociada a una amplia batería de verbos - de hecho, representa la opción estructural mayoritaria en el marco de los CADV entendidos en un sentido amplio-, conserva la fijación preposicional en la eferencia (el CADV eferente está encabezado exclusivamente por la preposición de), la posibilidad de tematizar esta función y la imposibilidad de posponer el CADV eferente al aferente y, en consecuencia, de tematizar el CADV aferente sin formar bloque con el eferente.

Asimismo, conviene resaltar que la preposición de los complementos locativos está especializada en los CADV (complementos de lugar regidos), sean estos simples o complejos. En contrapartida, los complementos de lugar con desde remiten en todos los casos a entidades funcionales adjuntas que muestran una absoluta libertad posicional y que, dada su naturaleza adjunta, se pueden combinar, en estructuras de verbos de desplazamiento (v.gr., acercarse, bajar, 
descender, elevar, ir, lanzar, llegar, llevar, subir o venir), con CADV aferentes y complementos intermedios de extensión y, en el marco de configuraciones de verbos de modo de desplazamiento (v.gr., correr, pasear o saltar), con complementos intermedios aferentes y de extensión, además de con entidades verbales que no pertenecen a estas categorías sintáctico-semánticas.

\section{Bibliografía}

BOONS, J. P. "Préliminaires à la classification des verbes locatifs: les compléments de lieu, leurs valeurs aspectuelles". Linguisticae Investigationes, 1985, 9 (2) , p. 195-267.

CIFUENTES HONRUBIA, J. L. "Sobre las construcciones locales en español". Estudios de Lingüística, 1988-1989, 5, p. 145-181.

COSERIU, E. Lecciones de Lingüística general. Madrid: Gredos, 1981.

CREGO GARCÍA, M. V. El complemento locativo en español. Los verbos de movimiento y su combinatoria sintáctico-semántica. Santiago de Compostela: Universidade, 2000. (Lalia Series Maior; 12).

DERVILLEZ-BASTUJI, J. Structures des relations spatiales dans quelques langues naturelles. Introduction à una théorie sémantique. Genève: Droz, 1982.

GARCÍA-MIGUEL, J. M. Transitividad y complementación preposicional en español. Santiago de Compostela: Universidade, 1995. (Verba, Anexo; 40).

GONZÁLEZ GARCÍA, L. "Frases nominales y preposicionales, ¿construcciones endocéntricas o exocéntricas?". Verba, 1995, 22, p. 543-557.

GUILLET A. y Ch. LECLÈRE. La structure des phrases simples en français. Constructions transitives locatives. Genève: Droz, 1992.

GUTIÉRREZ ORDÓÑEZ, S. "Estructuras ecuandicionales". En: DEMONTE V. (ed.). Gramática del Español. México: El Colegio de México, 1994, p. 363-383.

- "¿Hablamos del suplemento?". En: CASADO VELARDE, Manuel et al. (eds.). Scripta Philologica in memoriam Manuel Taboada Cid. A Coruña: Servicio de Publicacións da Universidade da Coruña, 1996, p. 433-451. [Trabajo también publicado en GUTIÉRREZ ORDÓÑEZ S. La oración y sus funciones. Madrid: Arco/Libros, 1997, p. 175-194.]

— "Reflexiones sobre la función incidental". En: IGLESIAS BANGO M. (ed.). Gramma-Temas 2. León: Universidad de León, 1997, p. 111-156.

HJELMSLEV, L. Omkring sprogteoriens grundlaeggelse. Copenhague, 1943. Cito por la trad. esp. de DÍAZ DE LIAÑO, J. L. Prolegómenos a una teoría del lenguaje. Madrid: Gredos, 1974.

JIMÉNEZ JULIÁ, T. "Endocentrismo y exocentrismo en un marco funcional". En: IGLESIAS BANGO M. (ed.). Gramma-Temas 2. León: Universidad, 1997, p. 297-331. 
JIMÉNEZ JULIÁ, T. "Núcleos en gramática constitutivo-funcional". Verba, 2000, 27, p. 87-132.

MARTÍNEZ, J. A. Cuestiones marginadas de Gramática Española. Madrid: Istmo, 1994.

MORERA PÉREZ, M. Estructura semántica del sistema preposicional del español moderno y sus campos de uso. Puerto del Rosario: Cabildo Insular de Fuerteventura, 1988.

ROJO, G. "La función sintáctica como forma de significante". Verba, 1979, 6, p. 107-151.

— Aspectos básicos de sintaxis funcional. Málaga: Ágora, 1983.

— "Sobre los complementos adverbiales". Jornadas de Filología / Profesor F. Marsá. Barcelona: Universidad de Barcelona, 1990, p. 153-171.

- y T. JIMÉNEZ JULIÁ. Fundamentos del análisis sintáctico funcional. Santiago de Compostela: Universidade, 1989. (Lalia; 2)

SOMERS, H. L. "On the Validity of the Complement-Adjunct Distinction in Valency Grammar". Linguistics, 22. 1984, p. 507-530.

TRUJILLO, R. "Notas para un estudio de las preposiciones españolas". Thesaurus, 26, 1971, p. 234-279.

\section{Nómina de textos:}

\section{Ensayo:}

LIN: $\quad$ BUNGE, M. Lingüística y filosofía. Barcelona: Ariel, 1983.

RAT: $\quad$ SÁNCHEZ FERLOSIO, R. La homilía del ratón. Madrid: El País, 1986.

TIE: $\quad$ PAZ, O. Tiempo nublado. Barcelona: Seix Barral, 1983.

USO: MARTÍN GAITE, C. Usos amorosos de la postguerra española. Barcelona: Anagrama, 1988.

\section{Narrativa:}

CAR: $\quad$ COLINAS, A. Larga carta a Francesca. Barcelona: Seix Barral, 1986.

CRO: GARCÍA MÁRQUEZ, G. Crónica de una muerte anunciada. Madrid: Mondadori, 1987.

DIE: $\quad$ PONIATOWSKA, E. Querido Diego, te abraza Quiela y otros cuentos. Madrid: Alianza/Era, 1987.

GLE: $\quad$ CORTÁZAR, J. Queremos tanto a Glenda. Madrid: Alfaguara, 1981.

HIS: $\quad$ BIOY CASARES, A. Historias desaforadas. Madrid: Alianza, 1986. 
JOV: $\quad$ ALDECOA, J. R. Porque éramos jóvenes. Barcelona: Seix Barral, 1986.

LAB: MENDOZA, E. El laberinto de las aceitunas. Barcelona: Seix Barral, 1982.

MIR: $\quad$ GUELBENZU, J. M. La mirada. Madrid: Alianza, 1987.

PAI: GOYTISOLO, J. Paisajes después de la batalla. Barcelona: Montesinos, 1982.

SON: $\quad$ SAMPEDRO, J. L. La sonrisa etrusca. Madrid: Alfaguara, 1985.

SUR: GARCÍA MORALES, A. El sur (seguido de Bene). Barcelona: Anagrama, 1985.

TER: MARTÍNEZ DE PISÓN, I. La ternura del dragón. Barcelona: Anagrama, 1988.

\section{Lengua oral:}

BAI: $\quad$ BARRENECHEA, A. M. El habla culta de la ciudad de Buenos Aires. Materiales para su estudio (tomo 2). Buenos Aires: Instituto de Filología y Literatura hispánicas Dr. Amado Alonso, 1987.

MAD: ESGUEVA, M. y M. CANTARERO (eds.). El habla de la ciudad de Madrid. Materiales para su estudio. Madrid: CSIC (Miguel de Cervantes), 1981.

SEV: PINEDA, M. A. de (ed.). Sociolingüística andaluza 2. Material de encuestas para el estudio del habla urbana culta de Sevilla. Sevilla: Universidad de Sevilla, 1983.

\section{Prensa:}

1VO: $\quad$ La Voz de Galicia (30/10/91).

2VO: $\quad$ La Voz de Galicia (22/11/91).

3VO: $\quad$ La Voz de Galicia (23/11/91).

\section{Teatro:}

1IN: OLMO, L. y P. ENCISO. Teatro infantil I. Madrid: Ed. Antonio Machado, 1987.

2IN: OLMO, L. y P. ENCISO. Teatro infantil II. Madrid: Ed. Antonio Machado, 1987.

AYE: $\quad$ DÍAZ, J. Ayer, sin ir más lejos. Madrid: Ed. Antonio Machado, 1988.

CAI: $\quad$ BUERO VALLEJO, A. Caimán. Madrid: Espasa-Calpe, 1981.

CIN: $\quad$ REINA, M. M. La cinta dorada. Madrid: Ed. Antonio Machado, 1989. 
COA: FERNÁN GÓMEZ, F. La coartada. Madrid: Ed. Antonio Machado, 1987.

HOM: $\quad$ SALOM, J. Un hombre en la puerta. Martín Pancorbo, 1984.

HOT:6 GALA, A. El hotelito. Madrid: Ed. Antonio Machado, 1988.

MOR: $\quad$ ALONSO DE SANTOS, J. L. Bajarse al moro. Madrid: Ed. Antonio Machado, 1987.

OCH: DIOSDADO, A. Los ochenta son nuestros. Madrid: Ed. Antonio Machado, 1990.

PAS: $\quad$ REINA, M. M. El pasajero de la noche. Madrid: Ed. Antonio Machado, 1988.

ZOR: $\quad$ NIEVA, F. Te quiero, zorra. Madrid: Ed. Antonio Machado, 1989. 
